\title{
The Impact of the Global Pandemic on Selected Aspects of Sustainable Tourism in the Czech Republic
}

\author{
Jana Stuchlíková ${ }^{1, *}$, and Milena Botlíková ${ }^{1}$ \\ ${ }^{1}$ Silesian University in Opava, Faculty of Philosophy and Science, Institute of Spa, Gastronomy and \\ Tourism, Masarykova 343/37, 74601 Opava, Czech Republic
}

\begin{abstract}
.
Research background: The overall impact of coronavirus has some positives and negatives on the tourism sector and thus on other downstream sectors. The stagnation of tourism will make it easier for overcrowded tourist centers, which corresponds to the goals of sustainable tourism. On the other hand, negatives can be attributed to it. The Covid -19 epidemic caused the decline in business activities in tourism to almost zero, not only in the Czech Republic, but in the entire global area. If we consider with the intention that a large part of tourism enterprises is dependent on foreign clients, then the steps necessary to prevent the further spread of the epidemic were fatal for many enterprises and contribute to rising unemployment, reducing public budget revenues, etc. It is clear that the functioning of tourism will not return to pre-coronavirus and will be gradual. Businesses will need to adapt their services and find new ways to distribute them.

Purpose of the article: The aim of the paper is to map the effect of coronavirus on selected aspects of sustainable tourism in the Czech Republic.

Methods: We used primary data obtained from controlled interviews with the operators of the monitored facilities and secondary data (EUROSTAT, CSO).

Findings \& Value added: The paper includes models of the impact of coronavirus in the field of tourism, focusing mainly on accommodation and catering establishments.
\end{abstract}

Keywords: Sustainable tourism; economic sustainability; tourism businesses; coronavirus; models of the impact of coronavirus on tourism

JEL Classification: $A 19 ; M 1 ; Z 30$

\footnotetext{
*Corresponding author: jana.stuchlikova@,fpf.slu.cz
} 


\section{Introduction}

The effect of the global COVID-19 pandemic on sustainable tourism is unquestionable. Severe acute respiratory syndrome, coronavirus, is currently spreading at an alarming rate worldwide, leading to the 2019 coronavirus pandemic [1]. Without a vaccine and with limited medical capacity to treat the disease, non-pharmaceutical interventions are the main strategy to control the pandemic. Unprecedented global travel restrictions and orders to stay at home are causing the most serious disruption of the global economy since World War II. Due to international travel bans, which affect more than $90 \%$ of the world's population, and widespread restrictions on public gatherings and community mobility, tourism has largely ceased in March 2020. The first evidence of repercussions on air transport, cruises and accommodation was devastating. Although the first UNWTO forecasts for 2020 are very uncertain, they suggest that the number of international arrivals could be reduced by 20 $30 \%$ compared to 2019 , and according to current developments, this number will be even higher. Tourism is particularly vulnerable to measures against pandemics due to limited mobility and social distance. It is certain that a pandemic will change society, including economy and tourism. It is necessary to consider why COVID-19 is an analogy of the ongoing climate crisis and why the volume growth tourism model promoted by UNWTO, ICAO, CLIA, WTTC and other tourism organizations needs to be questioned [2].

The words of the WHO Director-General, who stated on 3 April 2020, can also be confirmed: "COVID-19 is much more than just a health crisis. We are all aware of the profound social and economic consequences of a pandemic (WHO, 2020). "Such consequences are the result of countermeasures, such as locking and global reductions in production and consumption, exacerbated by cascading effects through international supply chains. The global multiregional macroeconomic model captures direct and indirect side effects in terms of social and economic losses, as well as the environmental impact of the pandemic. Based on information from May 2020, it can be shown that global consumption losses reach $\$ 3.8 \mathrm{tr}$, which causes significant job losses (147 million full-time equivalents) and income $(\$ 2.1 \mathrm{tr})$. Global atmospheric emissions are reduced by $2.5 \mathrm{Gt}$ of greenhouse gases, 0.6Mt of PM2.5 and 5.1Mt of SO (2) and NOx. While Asia, Europe and the US were the regions with the most direct impact and transport and tourism were the sectors directly affected, the indirect effects transmitted within international supply chains are felt by the whole world economy. These wave effects underline the intrinsic link between the socioeconomic and environmental dimensions and underline the challenge of addressing unsustainable global patterns. How humanity responds to this crisis will define the postpandemic world [3].

According to the latest data from the World Tourism Organisation (UNWTO), there was a $65 \%$ year-on-year drop in international tourist arrivals in the first half of this year (440 million arrivals), then even a 93\% drop in June, with foreign tourist numbers likely to fall by 58 to $78 \%$ in 2020 . The massive drop in demand translated into a loss of international tourism revenues in the first half. It reached $\$ 460$ billion, five times more than during the 2009 global economic and financial crisis. Returning to 2019 levels will take 2.54 years, according to UNWTO. Small firms, in particular, are vulnerable, providing $80 \%$ of global tourism. $90 \%$ of states have closed World Heritage sites. $90 \%$ of museums were also closed, $13 \%$ of which are likely to never open again. (UNESCO, 2020). Although member countries of the Organization for Economic Co-operation and Development (OECD) are largely considered a high index of human development and highincome economies, evidence continues to reveal an existential gap between member countries that leads to environmental sustainability. In addition, the impact of the influx of international tourism, urbanization and energy consumption is significant and damages the quality of the environment [4]. 
In the midst of this crisis, tourism professionals are targeting communities in tourist destinations, focusing on their safety, well-being and the costs they will incur as a result of the cessation of tourism activities. The new coronavirus (COVID-19) is a challenge for the world. Twenty years ago, a concept paper was published, which concluded that the sustainable development of tourism is an unviable goal. Specifically, the study stated that the development of environmentally friendly tourism [5] (sustainable tourism) is necessary; however, sustainable development through tourism is unattainable. Despite the continuing convergence between tourism and sustainable development in academia and politics, not only has this argument proved to be correct in practice over the past two decades, but there is also little evidence of a more sustainable tourism sector. The author of this document, R. Sharplay, is now returning to the theoretical relationship between tourism and sustainable development in the coronavirus era, with regard to recent transformations in the understanding of the concept of development and current approaches to sustainable development. Emphasizes the controversy surrounding the continued commitment to economic growth in development policy in general and tourism development in particular, and discusses sustainable dismantling of growth as an alternative approach to development and, in the context of growing concerns about climate change, the concrete consequences for tourism [6].

A number of tourist destinations, particularly major cities, are facing problems caused by excessive visitor growth, referred to as overtourism, and are trying through, for example, de-marketing, or management of visitor distraction or capacity to manage visitors and reduce the number of tourists in a particular place and time. The differences in tourism resources also show the spatial patterns of tourist flows representing the movement of tourists, on the basis of which they provide advice to promote balanced and sustainable tourism development. A new framework for analysing these patterns can currently be proposed, based on tourist digital footprint data collected from online travel diaries. Based on illustrative data from case studies, a framework combining traditional quantitative analysis and analysis of social networks is able to determine: the effect of distance loss and attraction popularity on the spatial patterns of tourist flows; the uneven distribution of major tourist hubs; and the existence of a structural hole phenomenon that forms the structure of a network with unbalanced power and intense internal competition; the creation of a key area for tourism. This difference in tourism resources between areas is then a challenge for the future development of tourism [7].

When it comes to rural territories, they often seek to increase tourist numbers. In doing so, they can benefit from, among other things, the entrepreneurial dynamics created by small tourism businesses, especially when they are linked to the life motivation of the relevant entrepreneurs. The benefits of small businesses in tourism to rural economies and their potential role in boosting rural development should not be neglected [8]. However, in the context of rapid urbanisation, many rural communities are experiencing a dramatic increase in the share of building land, leading to a decline in ecosystem services. Conflicting development goals are a primary challenge for sustainable rural development. Increasing household incomes is a primary challenge for rural development and harmonising the relationship between maintaining ecosystem services and increasing household incomes is crucial for rural communities [9].

At the moment of the global pandemic, people have been shown to make choices when choosing a destination especially based on where they are at least risk of contracting the coronavirus, leading to an enormous reduction in visitor numbers to foreign destinations and leisure preferences in smaller towns and rural areas as part of domestic tourism. COVID-19 is so widely recognised as a challenge or even a game changer for travel and tourism to make it more ethical, accountable and sustainable, even though some advocates of rapid industrial renewal oppose broader efforts to reform tourism. The fight to push for 
positive change therefore concerns both the proper role of tourism and tourism academics. The results of this effort will have an impact on the development of the field itself, on the education of tourism students and the future of tourism practices in the years ahead [10].

\section{Methodology}

A comparative analysis was used to obtain the necessary up-to-date data on the global impact of Coronavir, including its impact on sustainable tourism. Apart from the global aspects, we focused in more detail on the situation in the Czech Republic, especially in the area of catering, accommodation and transport services. Both the secondary data from objectively available sources and the primary data from the own survey conducted in the second half of August 2020 were used to determine how covid-19 affected the hotel and gastronomy business. Respondents were owners or operators of 9 accommodation and 16 catering establishments in the Moravian-Silesian Region. The research tool was a structured questionnaire.

\section{Results}

The coronavirus has a negative impact on tourism, but it has also produced a number of positives particularly in the context of sustainable tourism. Next, the question is whether and to what extent the coronavirus will be reflected in the development of sustainable tourism models, which were widely discussed in economic literature in the pre-coronavirus era. The need to analyse the links between sustainable tourism models and natural resource management appears essential. There are studies highlighting how proper management of public goods can lead to demand meeting on the one hand and creating opportunities for sustainable environmental development on the other [11]. Although the tourism sector significantly influences the economy of most destinations, the impacts of political, security, socio-economic and financial dynamics in the destination countries also play a decisive role [12]. Which also applies to the Czech Republic. Next, we give concrete examples of the positive and negative impacts of the coronavirus primarily in relation to local sustainable tourism.

\subsection{The Positive Impacts of Coronavirus}

Positive impacts include, in particular, reductions in air emissions largely due to restrictionsprimarily on air transport, where over the past two decades low-cost carriers operating short-haul flights that have session-high carbon emissions per passenger [13]. have expanded. Part of the reduction in air emissions is also due to the loss of lines in bus and train services coupled with reduced demand related to the declaration of an emergency, with school closures, maximum use of the home office and travel only in the most urgent cases. The lower carbon footprint was also due to a reduction in manufacturing activity in both heavy and light industry as a result of announced epidemiological measures and a consequent reduction in demand.

The reduction in demand in transport, industry and other downstream sectors has led to lower oil and fuel prices, which should at least partially offset the large losses of these entities. Waste volumes have also been significantly reduced, both in accommodation and catering establishments, which have effectively dampened their activities entirely, or to a minimum, and in industrial businesses. The stagnation of tourism has eased overcrowded tourist centres, correlated with the goals of sustainable tourism. This is also linked to the realisation of slower forms of life, slow travel, slow cities, etc., the support of local 
businesses and the preservation of local traditions and the environment [14]. On the other hand, more mass use of online technology can be included among the other positives. In some cases, there has also been an acceleration in the use of Big Data Analytics (BDA) to support the transformation of cities into smart destinations leading to facilitate the achievement of smart tourism goals and the contribution to sustainable tourism [15]. In the case of the Czech Republic, apart from Prague, Brno and others, Ostrava is already one of the intelligent cities, which applies smart solutions in the field of transport, water management and air protection [16].

\subsection{The Negative Impacts of Coronavirus}

The Covid-19 epidemic was the cause of the decline in business activities in tourism to almost zero not only in the Czech Republic, but in the entire global area. As part of the measure, hotels and restaurants were closed, and the flow of foreign tourists stopped.

The significant reduction or cancellation of mass events, such as congresses, conferences, trade fairs, sporting events or cultural events, is also one of the negative consequences of the pandemic, which is reflected primarily in other service sectors, including accommodation and catering facilities [17].

Given that a large proportion of tourism businesses are dependent on foreign clients, this means that it is fatal for many businesses, thanks to the steps taken to prevent the further spread of the epidemic. Businesses that managed to cope with the unfavorable situation in the first half of the year and found themselves at the limit of their possibilities are announcing that the chassis will not be able to cope with the next wave of the pandemic. In addition, there is an increase in unemployment, a decrease in revenue to public budgets and at the same time an increase in expenditure items and a consequent increase in government debt. Specific items showing the negative effects of coronavirus on tourism in the Czech Republic are listed in the following subchapter.

\subsection{Examples of the Effect of Coronavirus on Tourism in the Czech Republic}

According to data from the Czech Statistical Office, in 2019 foreign tourists in the Czech Republic made around 27.18 million overnight stays and spent around 124.1 billion. CZK, resulting in benefits for public budgets in multiplication at about $49.7 \mathrm{bn}$. CZK. Tourists from Italy, China and South Korea accounted for around $9.6 \%$ of overnight stays and accounted for around $11.8 \%$ of total consumption due to higher average daily spend. Tourism provided 144,000 job opportunities, in full-time equivalents. The Association of Hotels and Restraurations of the Czech Republic, in cooperation with Economic impacT, had already developed models of the potential impacts of the development of the epidemic on tourism in the Czech Republic in February 2020, but in the first 3 weeks of the pandemic alone, hotel occupancy in the Czech Republic fell by $96 \%$, a slight increase occurred during July and August thanks to domestic tourists, but since September the situation has been unfavorable again for hoteliers and restaurate, due to the coronavirus, due to further spread of the coronavirus

So, some 2 million people were missing. As surveys show, residents of the Czech Republic have been trying to save more since the second quarter, saving primarily on spending on services and on food [18]. 


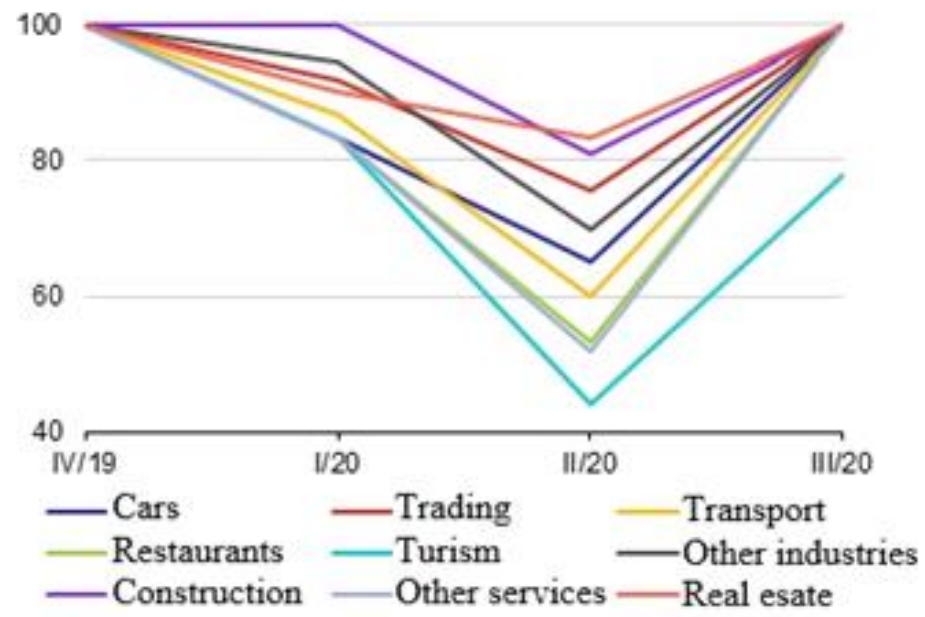

Fig. 1. Direct impact of the measure on gross value added

The measures will have the most significant impact on the services sector, especially tourism (index, unlimited traffic $=100$ ) Note: A return to 100 in the third quarter of 2020 does not mean reaching precoronavirus production levels, but a return to government and corporate quarantine measures of unrestricted operation.

Tourism accounts for $2.9 \%$ of Czech GDP, employs more than 240,000 people and is highly sensitive to any emergency. Up to 40,000 jobs are at risk in this sector, and if the coronavirus crisis were to last for a long time, the whole sector would be in huge trouble and could also threaten other downstream industries, for example the services sector. Apart from employed workers, there are a large number of self-employed people in domestic tourism who had no or minimal incomes. The state gave those individuals a one-time bonus of 25,000. Kc for part of the month of March and April, then 15,000 CZK for May and part of June, besides, business owners were exempted from paying social and health insurance.Currently, the State Investment Support Fund (SFPI) has set aside 3.3 billion crowns in the COVID program. Accommodation operators can apply for a state subsidy for forced spring closure due to a government measure against coronavirus until October 30, 2020. [19]. Hotels, motels and boats with four to five stars are entitled to the highest contribution 330 from 14 March to 24 May 2020330 crown. Three-star operations can get 300 crowns per room per night, hotels garni compensation 250 crowns. Accommodation with one and two stars and guesthouses can ask for 200 crowns per room. Camps, cottage settlements or tourist hostels are entitled to a subsidy of 100 crowns per room. Camps can only apply for a contribution for accommodation facilities, such as buildings with rooms or cottages [20].

For vouchers worth 4 thousand crowns. The state will contribute CZK 1 billion to spa facilities within the COVID spa program.

Revenues from tourism will fall to 158 billion crowns, ie almost half, compared to last year's estimate, compared to last year. So far, Prague has accounted for 60 percent of domestic tourism. Experts now expect a drop in consumption of about 70 percent.

63 percent of Czech adults went on summer vacation this year, which was 14 percentage points lower than last year. Meanwhile, 73 percent of Czechs spent it in the Czech Republic, compared with less than half last year. This is clear from a survey Perfect Crowd conducted for Home Credit, a credit firm. The main reasons were both fear of coronavirus infection and a smaller supply of more distant destinations, as well as people's 
fear associated with the emerging crisis. Nine out of ten respondents replied that the total cost of their summer holiday was up to 30,000 crowns.

The key is to find a common solution as soon as possible and at least partially compensate for the losses of the most affected fields, including accommodation services or tourism. "Unfortunately, everyone pays for the current situation around coronavirus. Entrepreneurs, employees and the state. At the moment, however, preventive measures are necessary and we are ready, together with the state, to mitigate the economic impacts as much as possible, "says Vladimír Dlouhý, President of the Czech Chamber of Commerce. His words can be followed by the question of how the Czech government is prepared for the next wave of the pandemic [21].

\subsection{Research Part - Opinions on Measures against Coronavirus by Operators of Accommodation and Catering Facilities in the Czech Republic}

You are free to Surveys and analyzes carried out at the level of the entire Czech Republic, for example by the Item agency at the level of customer behavior or the Association of Hotels and Restaurants, focusing on providers of accommodation and catering services, were supplemented by our own marketing research. Within the Moravian-Silesian Region, we conducted a survey among operators of accommodation and catering facilities in order to find out how covid-19 affected their business. We used the method of telephone inquiries in the period 15.-25. August 2020, the target group consisted - owners, executives, directors or operating small and medium accommodation and catering facilities, sample size - 25 business entities, of which 16 restaurants and 9 accommodation facilities. The research tool was a structured questionnaire lasting about 7 minutes.

The survey showed that in June and July the average occupancy in accommodation establishments was 20-30\%, the decrease in sales compared to the same period of 2019 was on average by $60-80 \%$ in accommodation establishments and 50-60\% in catering establishments. The media pressure on citizens related to the presentation of a dangerous infection in the region was considered by most companies as the main negative effect related to coronavirus $(73 \%)$. Among the measures they considered to be the biggest restriction of their business, $34 \%$ of respondents mentioned restrictions on the number of people (up to 100) and subsequent wearing of veils (28\%), followed by disinfection of premises, maintenance of spacing and reduction of operating hours. Regarding the specific support that respondents would welcome, most of them mentioned the following options: government subsidies, financial compensation for lost profits, tax exemptions and health and social insurance.

All respondents agreed that it was important for them to stabilize the situation and, if possible, at least approach the normal state that existed before the outbreak of the pandemic.

It will also be crucial to ensure that the economy restarts as soon as the coronavirus epidemic subsides. This should provide at least partial compensation to companies for the wage compensation of quarantined employees. Small-scale self-employed people are also an endangered group, who do not have to endure financially due to a 14-day outage due to quarantine measures.

\section{Discussion and Conclusion}

Humanity has faced an unprecedented outbreak of the Covid-19 pandemic since early 2020. The disease has begun to change economic, social and individual conventional behaviour and has a huge impact on civic life. 
In recent years, demand for tourism has grown repeatedly, bringing with it a number of problems related to sustainable tourism, among others. While the new pandemic has relieved overcrowded tourist centres, correlated with the goals of sustainable tourism, since hotels and restaurants have been closed as a precautionary measure against further spread, in addition to the closure of economies, the flow of foreign tourists has also ceased, which has not recovered even after the opening of tourism businesses, this near-zero or very limited demand poses an existential risk to most small and medium-sized businesses.

Current developments indicate that entrepreneurs and tourism workers alike will face a major crisis, the severity of which will depend on the duration of the current epidemic, but also on the capacity to rapidly rebuild tourism after it has passed. So it is also necessary to consider in advance steps to reduce the effects of the expected crisis on our economy and employment, including greater focus on innovation, digitisation, cooperation and sustainability in tourism. It is clear that the functioning of tourism will no longer return to pre-coronavirus levels and, given that it is one of the sectors most affected by the pandemic, the return will be gradual. Businesses will need to adapt their services and find new ways to distribute services using technology as a force for problem solving, connecting people, sharing information and organizing civic life. Thanks to COVID-19, the chances of greater use of modern technologies have increased and it can be assumed that they will be used, for example, in the creation of other intelligent cities, municipalities or regions. It is also likely that online platforms will be used more extensively, not only in tourism businesses. At the very least, these are new challenges for accessibility, usability and justice, including the Czech Republic.

The key is to find a common solution as soon as possible and at least partially compensate for the losses of the most affected fields, including accommodation services or tourism. "Unfortunately, everyone pays for the current situation around coronavirus. Entrepreneurs, employees and the state.

The paper was financed from the project Development of R\&D Capacities of the Silesian University in Opava CZ. 02.2.69 / $0.0 / 0.0 / 18 \_054$ / 0014696.

\section{References}

1. Qiu, R. T. R., Park, J., Li, S. N., Song, H. Y. (2020). Social costs of tourism during the COVID-19 pandemic. Annals of Tourism Research, 84, 102994.

2. UNWTO (2020, September 15). Restarting Tourism. Retrieved from: https://webunwto.s3.eu-west-1.amazonaws.com/s3fs-public/2020-05/UNWTO-GlobalGuidelines-to-Restart-Tourism.pdf

3. Gossling, S., Scott, D., Hall, C. M. (2020). Pandemics, tourism and global change: a rapid assessment of COVID-19. Journal of Sustainable Tourism, 29(1), 1-20.

4. Lenzen, M., Li, M., Malik, A., et al. (2020). Global socio-economic losses and environmental gains from the Coronavirus pandemic. Plos one, 15(7), e0235654.

5. Yoopetch, Ch., Nimsai, S. (2019). Science Mapping the Knowledge Base on Sustainable Tourism Development 1990-2018. Sustainability, 10(12), 4846.

6. Alola, A. A., Lasisi, Taiwo T., Eluwole, K. K., Alola, U. V. (2019). Pollutant emission effect of tourism, real income, energy utilization, and urbanization in OECD countries: a panel quantile approach Enviromental Science and Pollution Research, forthcoming article. 
7. Sgroi, F. (2020). Forest resources and sustainable tourism, a combination for the resilience of the landscape and development of mountain areas. Science of the Total environment, 736, 139539.

8. Sharpley, R. (2020). Tourism, sustainable development and the theoretical divide: 20 years on. Journal of Sustainable Tourism, 28(11), 1932-1946.

9. Zhang, K., Sun, X., Jin, Y. et al. (2020). Development models matter to the mutual growth of ecosystem services and household incomes in developing rural neighborhoods. Ecological indicators, 115, 106363.

10. Cunha, C., Kastenholz, E., Carneiro, M. J. (2020). Entrepreneurs in rural tourism: Do lifestyle motivations contribute to management practices that enhance sustainable entrepreneurial ecosystems? Journal of Hospitality and Tourism Management, 44, 215 226.

11. Hall, C. M. (2019). Constructing sustainable tourism development: The 2030 agenda and the managerial ecology of sustainable tourism. Journal of Sustainable Tourism, 27(7), 1044-1060.

12. Athari, Z. A., Alola, U. V., Ghasemi, M., Alola, A. A. (2020). The (Un)sticky role of exchange and inflation rate in tourism development: insight from the low and high political risk destinations. Current Issues in Tourism, forthcoming article.

13. Higgins-Desbiolles, F. (2020). The "war over tourism": challenges to sustainable tourism in the tourism academy after COVID-19. Journal of Sustainable Tourism, 28(2020), forthcoming article.

14. Werner, K., Griese, K-M., Bosse, Ch. (2019). The role of slow events for sustainable destination development: a conceptual and empirical review. Journal of Sustainable Tourism, forthcoming article.

15. Zeng, D., Tim, Y., Yu, J., Liu, W. Y. (2020). Actualizing big data analytics for smart cities: A cascading affordance study. International Journal of Information Management, 54, 102156.

16. City Ostrava (2019, June 4). The Moravian-Silesia Region and the City of Ostrava will introduce their smart technologies. Retrieved from: https://www.msk.cz/cz/doprava/moravskoslezsky-kraj-a-mesto-ostrava-predstavi-sve-chytre-technologie-129670/

17. Hř́bal, J. (2020, April 17). Real numbers and consequences covid-19. How the virus hit tourism. Retrieved from: https://jan-hospitality.com/reaina-cisla-covid19-viruszasahl-cestovni-ruch/

18. Machová, S. (2020, April 8). COVID impacts on tourism in detail. Retrieved from: https://tourdata.cz/dopady-covid/dopad-covid-19-na-cestovni-ruch-v-cr/

19. HK ČR. (2020, September 23). Tens of billions of crowns may be lost to companies and the state budget due to the coronavirus. Retrieved from: https://www.khkmsk.cz/desitky-miliard-korun-mohou-kvuli-koronaviru-tratit-firmy-istatni-rozpocet/

20. С̆TK (2020, September 16). There have already been 576 applications in the COVID accommodation scheme. Retrieved from: https://www.icot.cz/v-programu-covidubytovani-bylo-jiz-podano-576-zadosti/

21. Kupčíková, T. (2020, September 4). Analytics Effect Pandemic Covid-19. Retrieved from: https://tourdata.cz/dopady-covid/analyza-vlivu-pandemie-covid-19-na-konanihromadnych-akci-na-uzemi-cr/ 